九州大学学術情報リポジトリ

Kyushu University Institutional Repository

\title{
Surface structure determination of silica single layer on Mo(112) by LEED
}

Kinoshita, Tetsuhiro

Department of Molecular and Material Sciences, Kyushu University

Mizuno, Seigi

Department of Molecular and Material Sciences, Kyushu University

http://hdl. handle. net/2324/25608

出版情報：Surface Science. 605 (13/14)，pp.1209-1213，2011-07. Elsevier バージョン:

権利関係: (C) 2011 Elsevier B.V. 
Surface structure determination of silica single layer on Mo(112) by LEED

Tetsuhiro Kinoshita and *Seigi Mizuno

Department of Molecular and Material Sciences, Kyushu University, Kasuga, Fukuoka 816-8580, Japan

\begin{abstract}
The atomic structure of silica single layer on a Mo(112) substrate was determined by means of low-energy electron diffraction analysis. The best-fit structure was consistent with findings of previous studies [Phys. Rev. Lett. 95 (2005) 076103 and Phys. Rev. Lett. 103 (2009) 017601]. The unit cell is $\mathrm{c}(2 \times 2)-\mathrm{Si}_{2} \mathrm{O}_{5}$ and is composed of a two-dimensional network of $\mathrm{SiO}_{4}$ tetrahedrons. The tetrahedrons incline slightly to fit the silica network on the $\mathrm{Mo}(112)$ surface while maintaining the ideal Si-O bond length. Since there are no dangling bonds in the silica network, the surface is very stable even in the atmosphere.
\end{abstract}

Keywords: Low energy electron diffraction (LEED); Molybdenum; silicon oxides

* Corresponding author.

E-mail address: mizuno.seigi.918@m.kyushu-u.ac.jp (S. Mizuno) 


\section{Introduction}

Thin oxide films have received great attention for their numerous applications to integrated circuits and as protective films against corrosion, and as supports for metal nanoparticles in catalysts and sensors. Their importance will be further increased with the miniaturization of devices. The atomic-level structure of thin-film oxides must be elucidated in order to determine their properties, and these structures have been studied for their technological importance and for the sake of fundamental sciences. Especially, thin-film oxides on metal surfaces have been studied as support materials of catalytic reactions [1]. Although silica layers were obtained on $\operatorname{Mo}(110)$ and $\operatorname{Mo}(100)$ surfaces $[2,3]$, they could not be used as model cases because they were amorphous. On the other hand, Schroeder et al. obtained a crystalline silica layer on a Mo(112) surface, and it would be ideal as a support material for catalytic reactions [4-7]. Growth of crystalline silica thin layers on $\mathrm{Ni}(111), \operatorname{Pd}(100)$ and $\mathrm{Ru}(0001)$ has also been reported [8-10], and many applications for these materials as model support materials, devices, sensors and so on have been expected. Moreover, crystalline silica single layers were obtained on $\mathrm{SiC}(0001)$ and $\mathrm{SiC}(000 \overline{1})$ surfaces [11,12]. Their structures have been already determined and they are robust even in air.

Crystalline silica thin layers on $\operatorname{Mo}(112)$ have a $c(2 \times 2)$ unit cell [4], and their surface structures have been studied by several methods. Chen et al. studied the surface using low-energy electron diffraction (LEED), high-resolution electron energy-loss spectroscopy (HREELS) and scanning tunneling microscopy (STM), and proposed an isolated $\mathrm{SiO}_{4}$ model [13-15]. Weissenrieder and Todorva et al. proposed a network model using STM, infrared reflection absorption spectroscopy (IRAS), X-ray photoelectron spectroscopy (XPS) and density functional theory (DFT) calculation [16,17]. A similar network model was also proposed by Giordano et al. [18,19]. Recently, Seifert et al. solved the controversy between above two models using ion beam triangulation method [20,21]. The data clearly provided evidence for the network model. However, structural determination using diffraction methods has not yet been done. Quantitative LEED intensity analysis is one of the most powerful and reliable methods for surface structure determination; it has been used to determine many surface structures with good accuracy, e. $g$. $0.1 \AA$. In this study, we examined the Mo(112)-c(2×2)-silica structure by means of LEED analysis. The determined structure model is again consistent with the network model proposed by Weissenrieder and Todorova et al. 


\section{Experiment}

Experiments were carried out in an ultrahigh vacuum (UHV) chamber (the base pressure during experiments was better than $5 \times 10^{-7} \mathrm{~Pa}$ ) equipped with LEED optics (SPECTALEED, Omicron). A single-crystal Mo(112) disk (10 mm $\phi, 2 \mathrm{~mm}$ thick) was welded to a Ta wire $(0.7 \mathrm{~mm} \phi)$ for resistive heating. The sample was simultaneously heated by electron bombardment from a tungsten filament placed closed to the backside of the sample. The temperature was measured by a thermo spot sensor (FTZ6, Japan Sensor). First, the sample was cleaned by cycles of annealing in $1 \times 10^{-5} \mathrm{~Pa}$ oxygen at $1200 \mathrm{~K}$ and flashing to $2200 \mathrm{~K}$ in UHV. A clear $(1 \times 1)$ LEED pattern was observed as reported in Ref. 22. Secondly, the sample surface was oxidized for $10 \mathrm{~min}$ in $5 \times 10^{-6} \mathrm{~Pa}$ oxygen at $850 \mathrm{~K}$. Finally, silicon was deposited on the sample from a high-temperature $\mathrm{Si}$ wafer heated by direct resistive heating. The silicate film was prepared by $\mathrm{Si}$ deposition for $5 \mathrm{~min}$ in $5 \times 10^{-5} \mathrm{~Pa}$ oxygen at $800 \mathrm{~K}$, followed by annealing for $5 \mathrm{~min}$ at $1200 \mathrm{~K}$ in UHV. A clear $\mathrm{c}(2 \times 2)$ LEED pattern was observed after this treatment as previously reported in Ref. 4.

The LEED spot intensities were measured by a digital charge-coupled device camera with a computer-controlled data acquisition system [23]. For structural analysis, the intensity versus electron beam energy spectra $[I(E)$ curves] of the LEED spots were measured within an incident energy range of 50-400 eV. The summation of energy ranges of inequivalent $I(E)$ curves, $\Delta E$, were 1647 and $2934 \mathrm{eV}$ for clean Mo(112)-(1×1) and $\mathrm{c}(2 \times 2)$-silicate surfaces, respectively. A Barbieri-Van Hove symmetrized automated tensor LEED package was used to determine the atomic positions [24]. Thirteen phase shifts were used to represent atomic scattering. The dumping of incident electrons was represented by an imaginary part of the inner potential, $V_{0 \mathrm{i}}$, of $-5.0 \mathrm{eV}$. Pendry's reliability factor $\left(R_{\mathrm{P}}\right)$ was used to direct the automated search algorithm [24,25]. The best agreement between experimental and theoretical $I(E)$ curves involved minimizing the $R_{\mathrm{P}}$. Errors in the structural parameters were estimated from the variance of the $R_{\mathrm{P}}, \Delta R=R_{P}\left(8\left|V_{0 i}\right| / \Delta E\right)^{1 / 2} \quad[25]$.

\section{Results and Discussion}

\subsection{Structural determination of the clean $\operatorname{Mo}(112)-(1 \times 1)$ surface}

First we examined the structure of the clean $\operatorname{Mo}(112)-(1 \times 1)$ surface. The LEED pattern of the clean Mo(112) surface is shown in Fig. 1(a). The structure had been determined 
by Kolthoff et al. using LEED analysis and is an ideally truncated crystal surface [22]. The structure model is shown in Fig. 2. There is one mirror plane displayed by the dashed line. The unit cell is shown by a rectangle with side lengths of $4.45 \AA$ and 2.73 $\AA$. The bulk layer distance toward the [112] direction is $1.28 \AA$. The surface perpendicular stacking has a 6-layer period with a 2-layer period toward the [110] direction and a 3-layer period toward the [11]] direction.

The structural parameters obtained from this study are shown in Table 1. Pendry's reliability factor became 0.193 after relaxation of the interlayer distances. We used seven inequivalent beams, and the total energy range was $1647 \mathrm{eV}$. The calculated $I(E)$ curves agreed with the experimental $I(E)$ curves very well as shown in Fig. 3. The Debye temperatures were fitted to $150,175,250,350,450$ and $450 \mathrm{~K}$ for each Mo layer from the surface topmost layer to the 6th layer, respectively. Interlayer distances calculated from Table 1 were 1.11, 1.35, 1.22, 1.32 and $1.27 \AA$ from the surface and show a typical surface relaxation. This was also consistent with previous LEED analyses $(1.09,1.31,1.26$ and $1.29 \AA$ from surface) [22]. The total energy range used in the previous study was $991 \mathrm{eV}$ and the obtained $R_{\mathrm{P}}$ was 0.205 . The present study had a larger total energy range (1647 eV) and a smaller $R_{\mathrm{p}}$ value $(0.193)$.

\subsection{Structural determination of the $\operatorname{Mo}(112)-c(2 \times 2)$-silica surface}

The LEED pattern of the silica surface is shown in Fig. 1(b). A sharp c(2×2) pattern was observed as in previous studies after the sample treatment of silicon deposition, oxidation and annealing $[4,13,17]$. We have examined the isolated silica model, the network model and other possible models by LEED analysis. The eleven examined Mo(112)-c(2×2)-silica models are shown in Fig. 4. Every model has one mirror plane indicated by a dashed line. Model 1 is the network model proposed by Weissenrieder and Todorva et al. and models 2-6 are its derivative models. Oxygen atoms sit on a bridge site, a top site or a hollow site of the Mo interface layer for models 1, 2 and 3, respectively. The topmost silicate networks sit on oxygen atoms, and the oxygen atoms connect Mo and Si atoms with bent bonds. Models 4-6 are similar to models 1-3, respectively, but the oxygen atoms bridge $\mathrm{Mo}$ and $\mathrm{Si}$ atoms with almost straight bonds similar to the case of the silica layer on an $\operatorname{SiC}(0001)$ surface [11]. Model 7 is the isolated $\mathrm{SiO}_{4}$ model proposed by Chen et al., and models 8-11 are related models [13]. Model 8 and 10 have two or three $\mathrm{SiO}_{4}$ units in their unit cells, respectively, and the $\mathrm{SiO}_{4}$ units are connected with each other. Model 9 shows a dimer of two $\mathrm{SiO}_{4}$ units sharing a corner oxygen. Model 11 resembles $\beta$ quartz, in which one $\mathrm{SiO}_{4}$ unit shares its 
four corner oxygen atoms with four neighboring $\mathrm{SiO}_{4}$ units. We used 14 inequivalent beams for LEED analysis. The obtained $R_{\mathrm{P}}$ values for the 11 models are shown in Table 2. Models 1 and 4 had small $R_{\mathrm{P}}$ values of 0.18 and 0.23 , and other models had $R_{\mathrm{P}}$ values greater than 0.5. Model 1 and model 4 have similar structures, and they also have similar theoretical $I(E)$ curves. However, their $R_{\mathrm{P}}$ values have meaningful differences of 0.05 compared to the $\Delta R$ value of 0.02 . The theoretical $I(E)$ curves for model 1 were plotted with the experimental $I(E)$ curves in Fig. 5 and they have quite nice agreement. Therefore, we concluded that model 1 is the correct model. It is consistent with the previous study using ion beam triangulation method [20,21]. The optimized best-fit model is shown in Fig. 6 and its structural parameters are listed in Table 3. The optimized Debye temperatures were 300, 300, 225, 300, 350, 400 and $450 \mathrm{~K}$ for $\mathrm{O}\left(1,1^{\prime}\right)$, $\mathrm{O}(2), \mathrm{Si}\left(1,1^{\prime}\right), \mathrm{O}\left(3,3^{\prime}\right), \mathrm{Mo}\left(1,1^{\prime}\right), \mathrm{Mo}\left(2,2^{\prime}\right)$ and $\mathrm{Mo}\left(3,3^{\prime}\right)$, respectively.

The diamond in the top view of Fig. 6 shows the $\mathrm{c}(2 \times 2)$ unit cell. The topmost layer in the unit cell consists of three oxygen atoms and one silicon atom. Two oxygen atoms were equivalent (marked 1 and 1') but the other oxygen atom was inequivalent (marked 2). The oxygen atoms bind with two equivalent silicon atoms (marked 1 and 1') to form a two-dimensional hexagonal network. The silicon atoms connect with the second layer of oxygen atoms (marked 3 and 3'). As a result, each silicon atom has four bonds, and the $\mathrm{SiO}_{4}$ units share the corner oxygen atoms. The second-layer oxygen atoms are located on the bridge site of the substrate Mo atoms (marked 1 and 1'). The structure of the Mo atoms is similar to the structure of clean $\operatorname{Mo}(112)-(1 \times 1)$, but the interlayer distances are different. The first and second interlayer distances are 1.21 and $1.34 \AA$, and these are much closer to the bulk value $(1.28 \AA)$ compared with the case of the clean surface (1.11 and $1.35 \AA$ ). It is reasonable that the surface covered by the silica layer and the surface relaxation becomes smaller than the clean surface.

\subsection{Features of the $\mathrm{Mo}(112)-\mathrm{c}(2 \times 2)-\mathrm{Si}_{2} \mathrm{O}_{5}$ surface}

The determined structure has no dangling bond in the silica layer and is composed of $\mathrm{Si}_{2} \mathrm{O}_{5}$. The bond lengths and bond angles of the silica layer are listed in Table 4 and are calculated from the best-fit structural parameters. Corresponding values obtained from an $\alpha-\mathrm{SiO}_{2}$ crystal [26] and $\mathrm{MoO}_{2}$ crystal [27], and previous results by first principles calculation [17] are also shown. Our results are very similar to the previous results by Todorova et al. The bond lengths are similar to the typical values in the bulk crystal. These results suggest the high stability of the $\mathrm{Mo}(112)-\mathrm{c}(2 \times 2)-\mathrm{Si}_{2} \mathrm{O}_{5}$ surface. Actually, we could observe clear $c(2 \times 2)$ LEED patterns after we exposed the sample to air 
without any treatment in the UHV chamber.

Similar network structures of silica or silicon oxynitride layers were reported on $6 \mathrm{H}-\mathrm{SiC}(000 \overline{1})$ and $6 \mathrm{H}-\mathrm{SiC}(0001)$ substrates $[11,12]$. Their structural parameters have been determined by LEED analysis. They are also terminated by silica single layer networks. The Si-O bond lengths are 1.61-1.63 $\AA$ and the Si-O-Si bond angles are $141-146^{\circ}$ and $180^{\circ}$. Though the bond lengths are quite similar to the case of the Mo surface, the bond angles are different. The topmost silica layer of the $\mathrm{SiC}$ substrate has a hexagonal unit cell, and the base of the $\mathrm{SiO}_{4}$ tetrahedron is parallel to the surface. The unit cells of silica on $\mathrm{SiC}$ are $(\sqrt{3} \times \sqrt{3}) \mathrm{R} 30^{\circ}$ and hexagonal with a lattice constant of $5.35 \AA$. On the other hand, the $\mathrm{SiO}_{4}$ tetrahedron on the Mo substrate inclines toward the [110] or [11 0 ] direction. The $\mathrm{O}\left(1,1^{\prime}\right)$ atoms come out to the vacuum and the $\mathrm{O}(2)$ atoms go down to the bulk. Since the $\mathrm{O}\left(3,3^{\prime}\right)$ atoms adsorb on the bridge site of the $\operatorname{Mo}(112)$, the $\mathrm{SiO}_{4}$ tetrahedron is inclined and the $\mathrm{Si}-\mathrm{O}-\mathrm{Si}$ bond angles are changed from the typical values. The unit cell of silica on Mo is quasi-hexagonal with a lattice constant of $5.23 \AA$. While the size of silica on Mo is smaller than that of silica on SiC, the Si-O bond lengths are almost equal due to the incline of the tetrahedrons. Only the Mo(112) surface is suitable for the growth of silica among the Mo crystal surfaces. Other low-index Mo surfaces do not have suitable cells for the growth of silica layers. Very recently, the growth of a double-layer sheet silica model on an $\mathrm{Ru}(0001)$ surface was reported [10]. The lattice constant of the hexagonal $\mathrm{Ru}(0001)-(2 \times 2)$ unit was $5.42 \AA$, and the size was suitable for the growth of similar silica network structures.

The STM images in the previous studies show chain-like features toward the [ $\overline{1} \overline{1} 1]$ directions $[15,17]$. This is very consistent with our model. The $\mathrm{SiO}_{4}$ tetrahedrons incline slightly, and the $\mathrm{O}\left(1,1^{\prime}\right)$ atoms protrude further than the $\mathrm{O}(2)$ atoms. As a result, the STM images might appear as stripes rather than a honeycomb. In the high-resolution STM images by Chen et al., single or double spots appear in the unit cell depending on the sample bias voltages [15]. The double spots are difficult to explain by the hexagonal silica layer. However, we have two equivalent $\mathrm{O}\left(1,1^{\prime}\right.$ ') atoms and one inequivalent $\mathrm{O}(2)$ atom in the unit cell, and it is likely to have electronic states to be showing two spots in the unit cell.

\section{Conclusion}

We have reinvestigated the structure of a clean Mo(112) surface and silica single layer on a Mo(112) surface. The clean Mo(112) surface has a crystal truncated structure with large surface relaxation. The silica single layer has a two-dimensional network of $\mathrm{SiO}_{4}$ 
tetrahedrons with a $\mathrm{c}(2 \times 2)-\mathrm{Si}_{2} \mathrm{O}_{5}$ unit cell. The tetrahedrons incline slightly to fit the Mo(112) substrate and have ideal Si-O bond lengths. The silica layer has no dangling bonds and this makes the surface very stable.

\section{Acknowledgements}

The authors thank Prof. M.-S. Chen for suggestions about sample preparation. This work was supported by a Grant- in-Aid for Scientific Research (KAKENHI 20340077) from the Ministry of Education, Culture, Sports, Science and Technology of Japan 
References

[1] H.-J. Freund, Surf. Sci. 500 (2002) 271.

[2] X. Xu and D. W. Goodman, Surf. Sci. 282 (1993) 323.

[3] J. W. He, X. Xu, J. S. Corneille, and D. W. Goodman, Surf. Sci. 279 (1992) 119.

[4] T. Schroeder, M. Adelt, B. Richter, M. Naschitzki, M. Bäumer, and H.-J. Freund, Surf. Rev. Lett. 7 (2000) 7.

[5] T. Schroeder, A. Hammoudeh, M. Pykavy, N. Magg, M. Adelt, M. Bäumer, H.-J. Freund, Solid State Electron. 45 (2001) 1471.

[6] T. Schroeder, J. B. Giorgi, M. Bäumer, and H.-J. Freund, Phys. Rev. B 66 (2002) 165422.

[7] T. Schroeder, M. Adelt, B. Richter, M. Naschitzki, M. Bäumer, H.-J. Freund, Microelectr. Rel. 40 (2002) 841.

[8] K. Manisha and Y. Murata, Appl. Phys. Lett. 80 (2002) 1921.

[9] Z. Zhang, Z. Jiang, Y. Yao, D. Tan, Q. Fu and X. Bao, Thin Solid Films 516 (2008) 3741 .

[10] D. Löffler, J. J. Uhlrich, M. Baron, B. Yang, X. Yu, L. Lichtenstein, L. Heinke, C. Büchner, M. Heyde, S. Shaikhutdinov, H.-J. Freund, R. Włodarczyk, M. Sierka and J. Sauer, Phys. Rev. Lett. 105 (2010) 146104.

[11] J. Bernhardt, J. Schardt, U. Starke, and K. Heinz, Appl. Phys. Lett. 74 (1999) 1084.

[12] T. Shirasawa, K. Hayashi, S. Mizuno, S. Tanaka, K. Nakatsuji, F. Komori, and H. Tochihara, Phys. Rev. Lett. 98 (2007) 136105.

[13] M.-S. Chen, A. K. Santra, and D. W. Goodman, Phys. Rev. B 69 (2004) 155404.

[14] S. Wendt, E. Ozensoy, T. Wei, M. Frerichs, Y. Cai, M.-S. Chen and D. W. Goodman, Phys. Rev. B 72 (2005) 115409.

[15] M.-S. Chen, D. W. Goodman, Surf. Sci. 600 (2006) L255.

[16] J. Weissenrieder, S. Kaya, J.-L. Lu, H.-J. Gao, S. Shaikhutdinov, H.-J. Freund, M. Sierka, T. K. Todorova, and J. Sauer, Phys. Rev. Lett. 95 (2005) 076103.

[17] T. K. Todorova, M. Sierka, J. Wessenrieder, J.-L. Lu, H.-J. Gao, S. Shaikhutdinov, and H.-J. Freund, Phys. Rev. B 73 (2006) 165414.

[18] L. Giordano, D. Ricci, G. Pacchioni and P. Ugliengo, Surf. Sci. 584 (2005) 225.

[19] D. Ricci and G. Pacchioni, Phys. Rev. B 69 (2004) 161307 (R).

[20] J. Seifert, D. Blauth, and H. Winter, Phys. Rev. Lett. 103 (2009) 017601.

[21] J. Seifert and H. Winter, Surf. Sci. 603 (2009) L109.

[22] D. Kolthoff, H. Pfnur, A. G. Fedorus, V. Koval, A. G. Naumovets, Surf. Sci. 439 (1999) 224. 
[23] S. Mizuno, H. Tochihara, A. Barbieri, M.A. Van Hove, Phys. Rev. B 52 (1995) R11658.

[24] M. A. Van Hove, W. Moritz, H. Over, P. J. Rous, A. Wander, A. Barbieri, N. Materer, U. Strarke and G. A. Somorjai, Surf. Sci. Rep. 19 (1993) 191.

[25] J. B. Pendry, J. Phys. C 13 (1980) 937.

[26] L. Levien, C. T. Prewitt and D. J. Weidner, A. Mineral. 65 (1980) 920.

[27] D. B. Rogers, R. D. Shannon, A. W. Sleight, and J. L. Gillson, Inorg. Chem. 8 (1969) 841. 
Figure captions

Fig. 1. LEED patterns of (a) Mo(112)-(1×1) clean surface and (b) $\operatorname{Mo}(112)-c(2 \times 2)$-silica surface.

Fig. 2. Top and side views of the Mo(112)- $(1 \times 1)$ clean surface.

Fig. 3. Experimental and theoretical $I(E)$ curves of the best-fit $\operatorname{Mo}(112)-(1 \times 1)$ clean surface model.

Fig. 4. Top and side views of examined structure models of the Mo(112)-c(2×2)-silica.

Fig. 5. Experimental and theoretical $I(E)$ curves for the best-fit structural model of the $\mathrm{Mo}(112)-\mathrm{c}(2 \times 2)-\mathrm{Si}_{2} \mathrm{O}_{5}$ surface.

Fig. 6. Top and side views of the best-fit $\mathrm{Mo}(112)-\mathrm{c}(2 \times 2)-\mathrm{Si}_{2} \mathrm{O}_{5}$ surface (model 1).

Table 1. Structural parameters obtained for the best-fit $\operatorname{Mo}(112)-(1 \times 1)$ clean surface model.

Table 2. Pendry's r-factors $\left(R_{\mathrm{p}}\right)$ for the models shown in Fig. 4.

Table 3. Structural parameters obtained for the best-fit $\mathrm{Mo}(112)-\mathrm{c}(2 \times 2)-\mathrm{Si}_{2} \mathrm{O}_{5}$ surface (model 1).

Table 4. Summary of bond lengths and bond angles. 

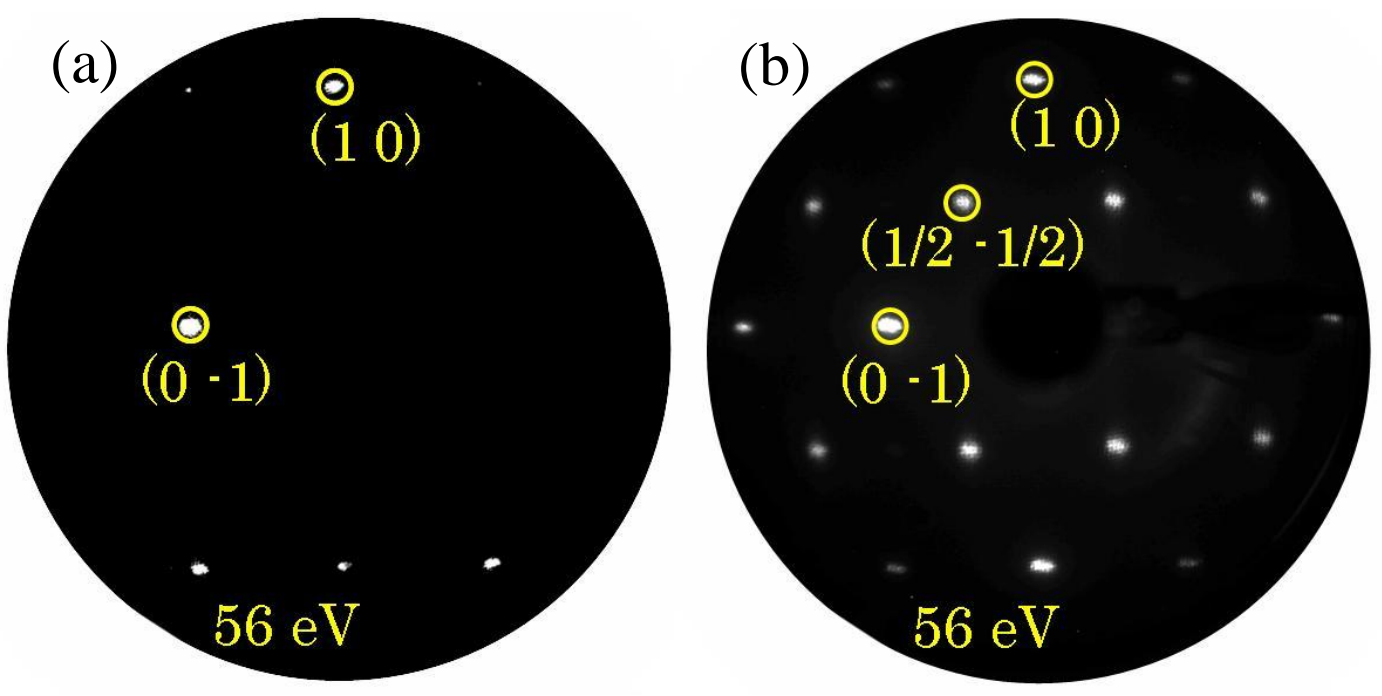

Fig. 1. LEED patterns of (a) Mo(112)- $(1 \times 1)$ clean surface and (b) $\operatorname{Mo}(112)-c(2 \times 2)$-silica surface. 


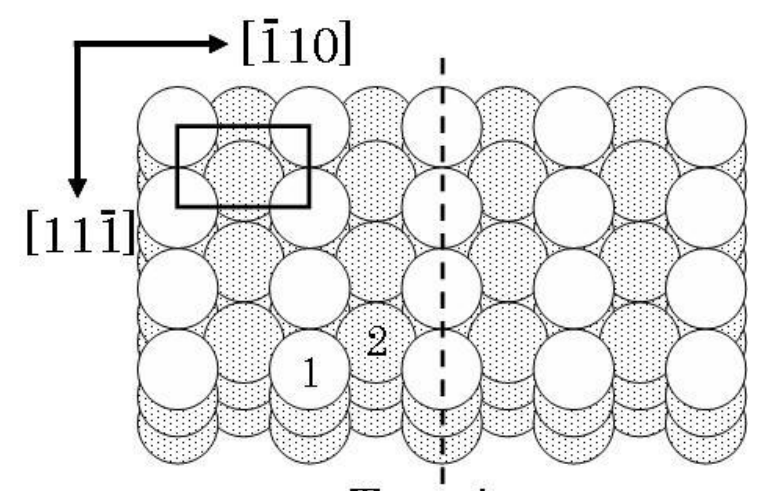

Top view

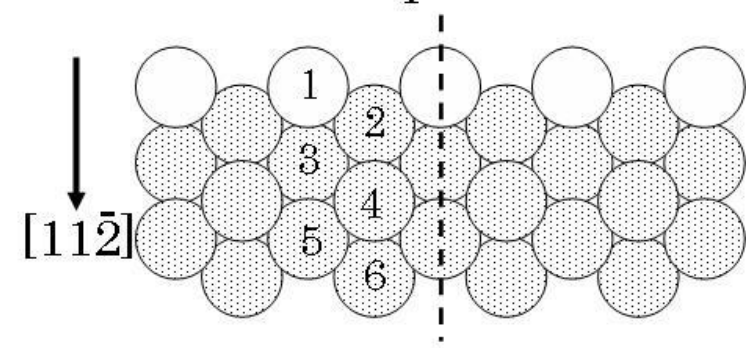

Side view

Fig. 2. Top and side views of the Mo(112)-(1×1) clean surface. 


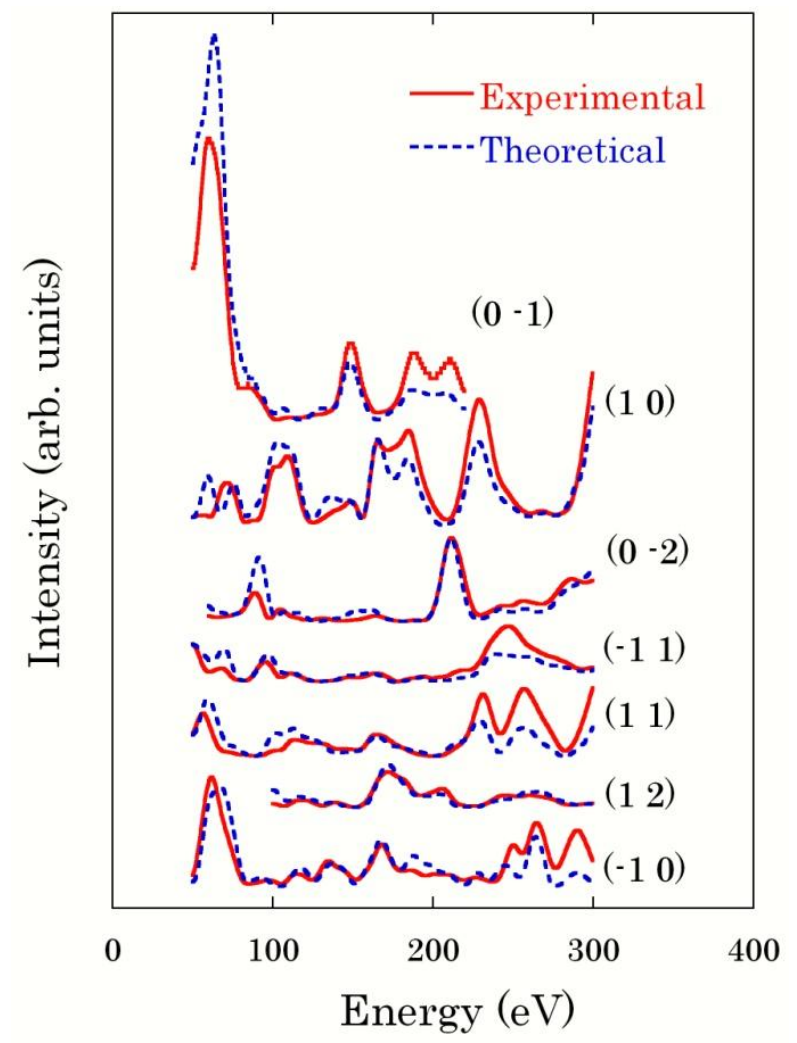

Fig. 3. Experimental and theoretical $I(E)$ curves of the best-fit Mo(112)-(1×1) clean surface model. 
Table 1. Structural parameters obtained for the best-fit Mo(112)-(1×1) clean surface model.

\begin{tabular}{lccccc}
\hline \hline \multicolumn{1}{c}{ Atom (No.) } & {$[1 \overline{1}](\AA)$} & {$[\overline{1} 10](\AA)$} & \multicolumn{2}{c}{$[11 \overline{1}](\AA)$} \\
\hline $\operatorname{Mo}(1)$ & -1.10 & \pm 0.02 & 2.23 & 0.91 & \pm 0.07 \\
$\operatorname{Mo}(2)$ & 0.01 & \pm 0.03 & 0.00 & -0.05 & \pm 0.05 \\
$\operatorname{Mo}(3)$ & 1.36 & \pm 0.03 & 2.23 & -0.97 & \pm 0.06 \\
$\operatorname{Mo}(4)$ & 2.58 & \pm 0.03 & 0.00 & 0.83 & \pm 0.06 \\
$\operatorname{Mo}(5)$ & 3.90 & \pm 0.04 & 2.23 & -0.02 & \pm 0.07 \\
$\operatorname{Mo}(6)$ & 5.17 & \pm 0.03 & 0.00 & -0.97 & \pm 0.07 \\
\hline \hline
\end{tabular}




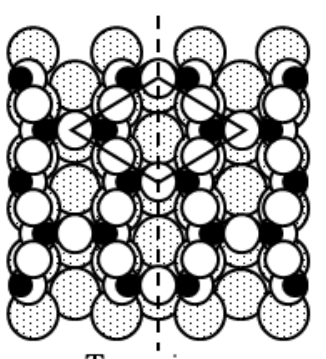

Top view

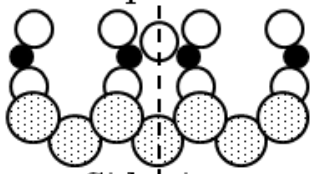

Side'view

Model 1
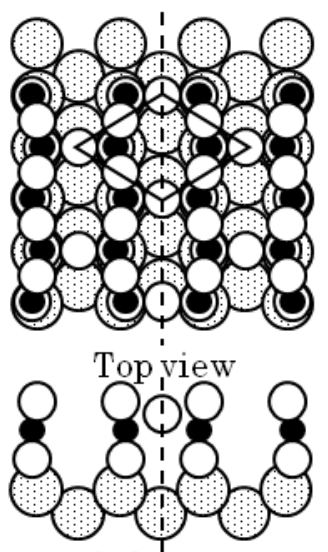

Side view

Model 5

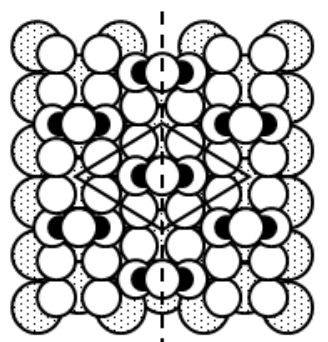

Top view

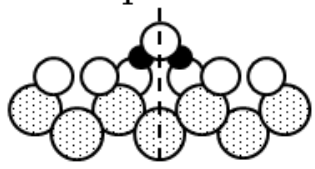

Side view

Model 9
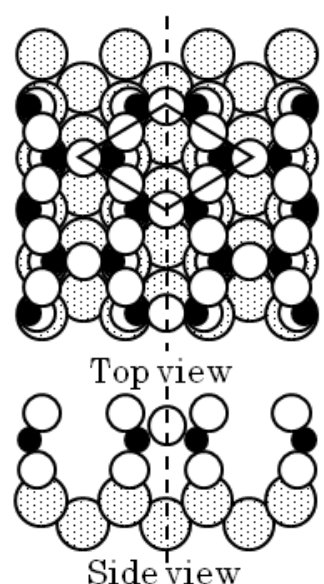

Model 2
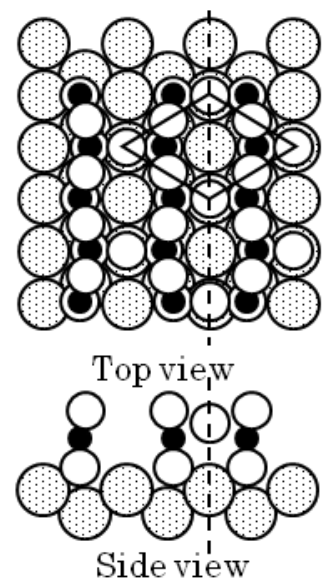

Side view

Model 6

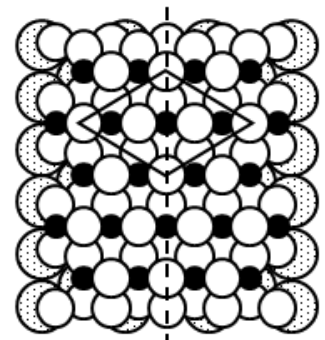

Top view

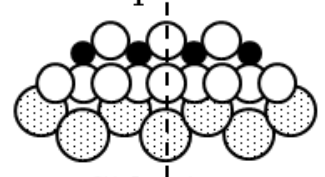

Side view

Model 10

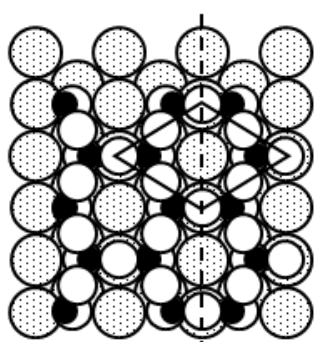

Top view

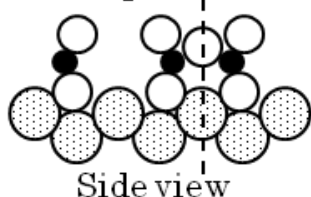

Model 3

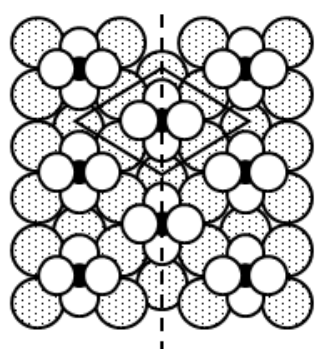

Top view

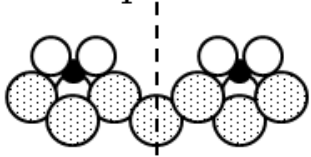

Side view

Model 7

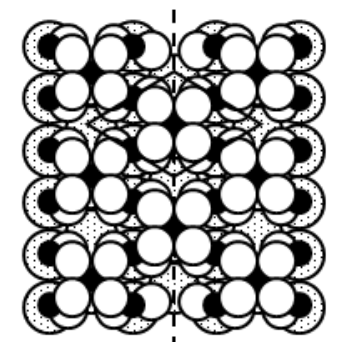

Top view

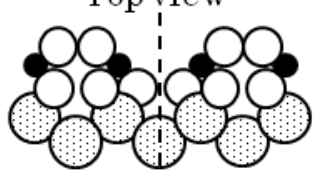

Side view

Model 11

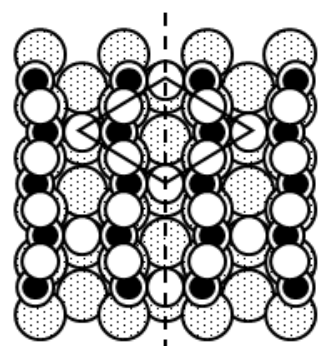

Top view

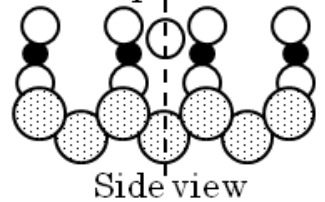
Model 4

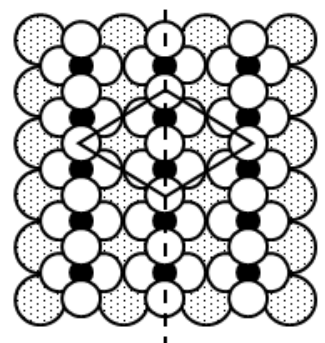

Top view

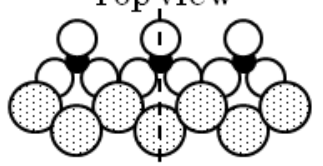

Side'view

Model 8

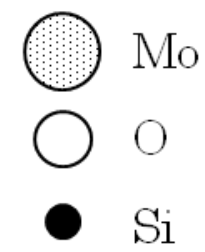

Fig. 4. Top and side views of examined structure models of the $\operatorname{Mo}(112)-c(2 \times 2)$-silica. 
Table 2. Pendry's r-factors $\left(R_{\mathrm{p}}\right)$ for the models shown in Fig. 4.

\begin{tabular}{cc}
\hline Model & $R_{\mathrm{p}}$ \\
\hline 1 & 0.18 \\
2 & 0.67 \\
3 & 0.58 \\
4 & 0.23 \\
5 & 0.60 \\
6 & 0.61 \\
7 & 0.66 \\
8 & 0.66 \\
9 & 0.66 \\
10 & 0.58 \\
11 & 0.57 \\
\hline \hline
\end{tabular}




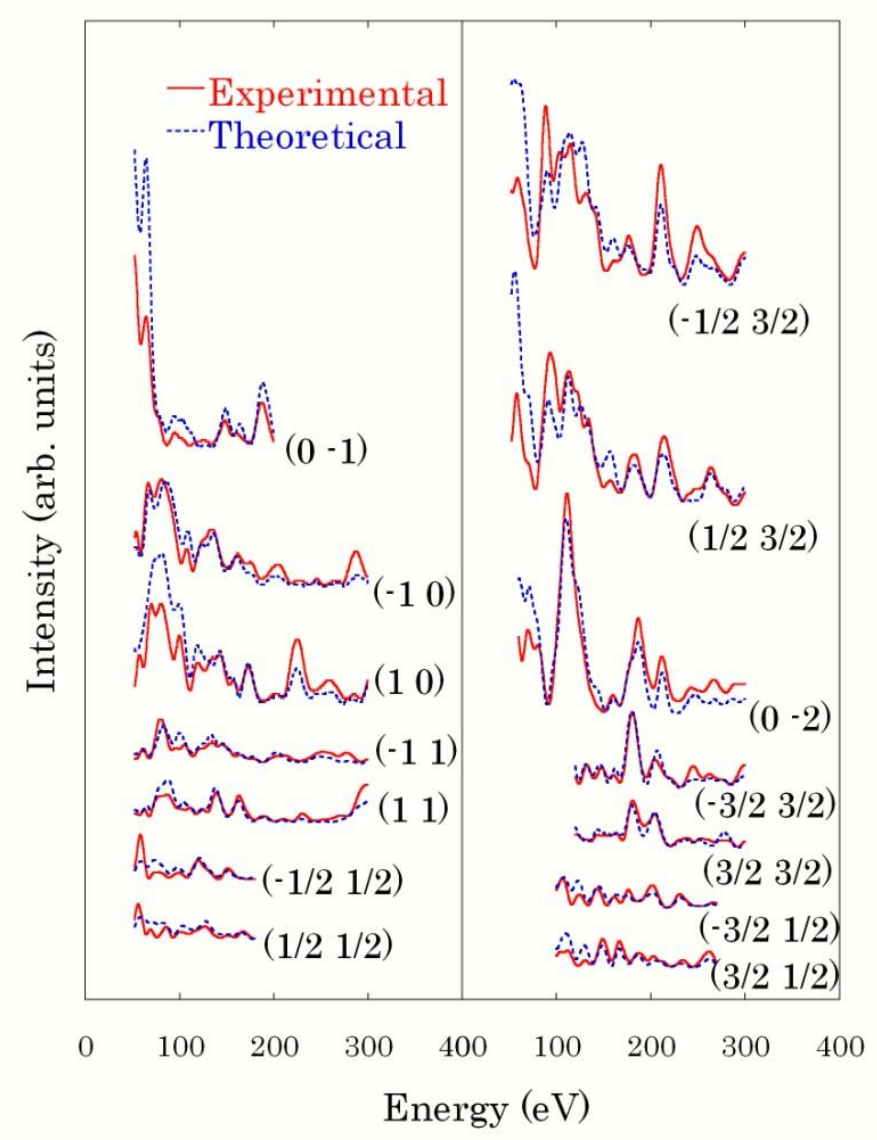

Fig. 5. Experimental and theoretical $I(E)$ curves for the best-fit structural model of the $\mathrm{Mo}(112)-\mathrm{c}(2 \times 2)-\mathrm{Si}_{2} \mathrm{O}_{5}$ surface. 

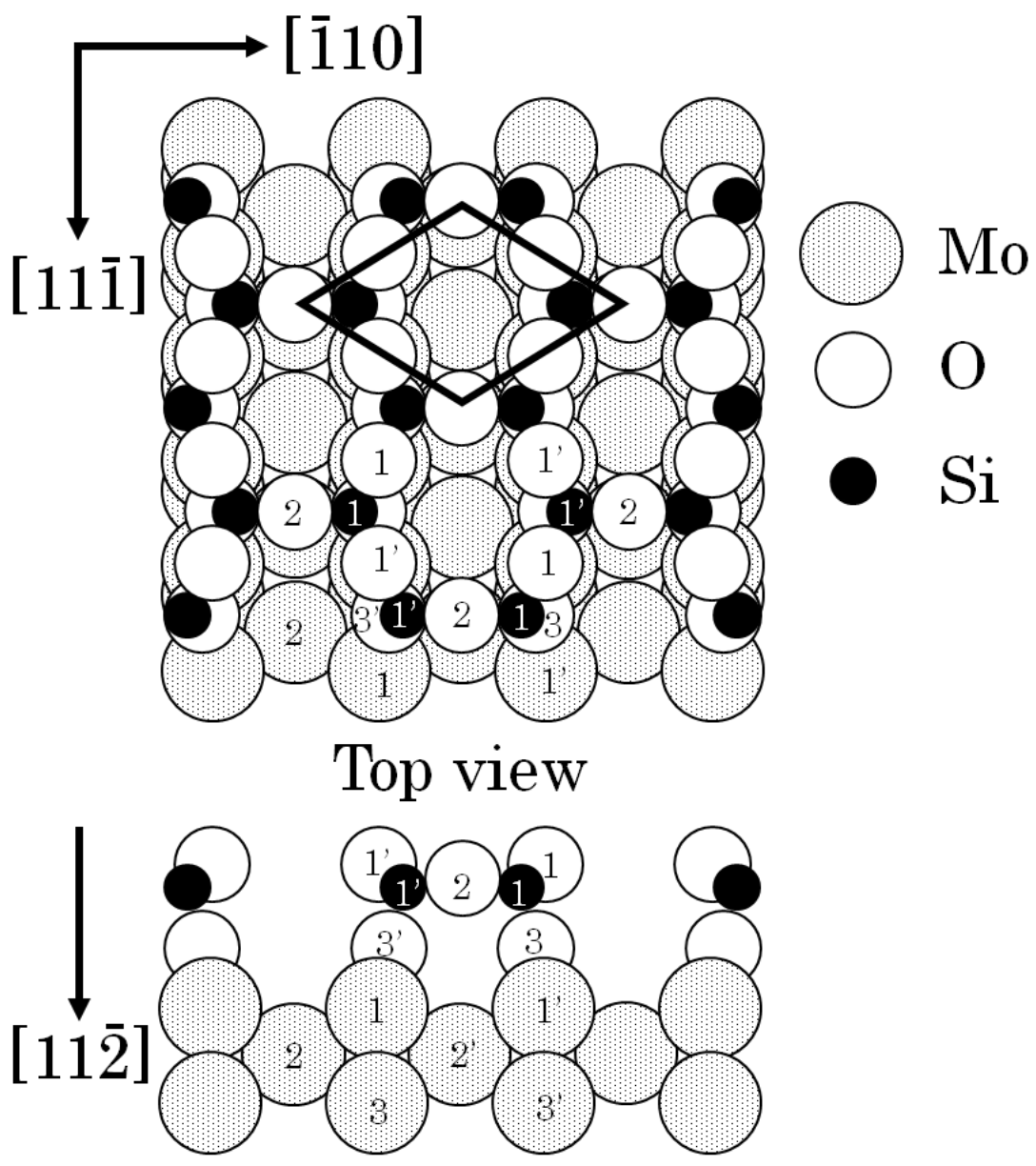

Side view

Fig. 6. Top and side views of the best-fit $\mathrm{Mo}(112)-\mathrm{c}(2 \times 2)-\mathrm{Si}_{2} \mathrm{O}_{5}$ surface (model 1). 
Table 3. Structural parameters obtained for the best-fit $\mathrm{Mo}(112)-\mathrm{c}(2 \times 2)-\mathrm{Si}_{2} \mathrm{O}_{5}$ surface (model 1).

\begin{tabular}{lccccccc}
\hline \hline Atom (No.) & {$[11 \overline{2}](\AA)$} & {$[\overline{1} 10](\AA)$} & \multicolumn{2}{c}{$[11 \overline{1}](\AA)$} \\
\hline $\mathrm{O}(1)$ & -0.68 & \pm 0.04 & 2.25 & \pm 0.12 & -1.32 & \pm 0.14 \\
$\mathrm{O}\left(1^{\prime}\right)$ & -0.68 & \pm 0.04 & 2.20 & \pm 0.12 & 1.41 & \pm 0.14 \\
$\mathrm{O}(2)$ & -0.29 & \pm 0.07 & 0.00 & & -0.01 & \pm 0.23 \\
$\mathrm{Si}(1)$ & -0.03 & \pm 0.02 & 1.58 & \pm 0.09 & 0.01 & \pm 0.07 \\
$\mathrm{Si}\left(1^{\prime}\right)$ & -0.03 & \pm 0.02 & 2.87 & \pm 0.09 & 2.74 & \pm 0.07 \\
$\mathrm{O}(3)$ & 1.56 & \pm 0.05 & 1.96 & \pm 0.12 & 0.04 & \pm 0.13 \\
$\mathrm{O}\left(3^{\prime}\right)$ & 1.56 & \pm 0.05 & 2.49 & \pm 0.12 & 2.77 & \pm 0.13 \\
$\mathrm{Mo}(1)$ & 3.18 & \pm 0.03 & 2.22 & \pm 0.05 & -1.33 & \pm 0.06 \\
$\operatorname{Mo}\left(1^{\prime}\right)$ & 3.18 & \pm 0.03 & 2.23 & \pm 0.05 & 1.40 & \pm 0.06 \\
$\operatorname{Mo}(2)$ & 4.39 & \pm 0.04 & 0.00 & & 3.20 & \pm 0.07 \\
$\operatorname{Mo}\left(2^{\prime}\right)$ & 4.39 & \pm 0.02 & 0.00 & & 0.50 & \pm 0.07 \\
$\operatorname{Mo}(3)$ & 5.71 & \pm 0.03 & 2.21 & \pm 0.06 & 2.26 & \pm 0.08 \\
$\operatorname{Mo}\left(3^{\prime}\right)$ & 5.71 & \pm 0.03 & -2.21 & \pm 0.06 & 2.26 & \pm 0.08 \\
\hline \hline
\end{tabular}


Table 4. Summary of bond lengths and bond angles.

\begin{tabular}{ccccc}
\hline \hline & This study & Ref. [17] & $\alpha-\mathrm{SiO}_{2}[26]$ & $\mathrm{MoO}_{2}[27]$ \\
\hline $\mathrm{Si}(1)-\mathrm{O}(1)(\AA)$ & 1.63 & 1.64 & 1.61 & \\
$\mathrm{Si}(1)-\mathrm{O}\left(1^{\prime}\right)(\AA)$ & 1.66 & 1.64 & 1.61 & \\
$\mathrm{Si}(1)-\mathrm{O}(2)(\AA)$ & 1.60 & 1.62 & 1.61 & \\
$\mathrm{Si}(1)-\mathrm{O}(3)(\AA)$ & 1.64 & 1.65 & 1.61 & \\
$\mathrm{Mo}(1)-\mathrm{O}(3)(\AA)$ & 2.14 & 2.11 & & 2.01 \\
$\mathrm{Si}(1)-\mathrm{O}(1)-\mathrm{Si}\left(1^{\prime}\right)$ & $134^{\circ}$ & $133^{\circ}$ & $144^{\circ}$ & \\
$\mathrm{Si}(1)-\mathrm{O}(2)-\mathrm{Si}\left(1^{\prime}\right)$ & $162^{\circ}$ & $163^{\circ}$ & $144^{\circ}$ & \\
\hline \hline
\end{tabular}

